\title{
Bibliography of Robert John (Yisrael) Aumann Scientific Papers
}

\author{
Victoria Kreps ${ }^{1,2}$ and Leon Petrosyan ${ }^{3}$ \\ 1 Institute for Regional Economic Studies RAS, \\ Serpuhovskaya st. 38, St. Petersburg, Russia \\ 2 National Research University Higher School of Economics, \\ 3 Kantemirovskaya st., St.Petersburg, Russia \\ 3 St.Petersburg State University, \\ 7/9, Universitetskaya nab., Saint-Petersburg 199034, Russia
}

The bibliography is published in connection with the ninetieth anniversary of the professor Robert John (Yisrael) Aumann.

On the eighth of June the outstanding Israeli American game theorist Robert John (Yisrael) Aumann celebrates his 90-anniversary. A professor at the Center for the Study of Rationality in the Hebrew University of Jerusalem in Israel, he received in 2005 the Nobel Memorial Prize in Economic Sciences for his work on conflict and cooperation through game-theory analysis. He shared the prize with Thomas Schelling. At the Hebrew University of Jerusalem Prof. Aumann created a flourishing game theory school which is one of the best in the world.

Prof. Aumann was the first plenary speaker at the First conference Game Theory and Management (GTM2007) held in June, 2007, in St.Petersbug and his lecture was followed by a lecture of his brilliant student, Sergiu Hart: the game-theory genealogy graph of Professor Aumann is immense and contains 172 descendants. The famous direct descendants (Doctoral students of Robert J. Aumann), listed in the chronological order, are

1. Bezalel Peleg, 1964

2. David Schmeidler, 1969

3. Shmuel Zamir, 1971

4. Elon Kohlberg 1973

5. Benyamin Shitovitz, 1974

6. Zvi Artstein, 1974

7. Sergiu Hart, 1976

8. Abraham Neyman, 1977

9. Yair Tauman, 1979

10. Dov Samet, 1981

11. Ehud Lehrer, 1987

12. Yossi Feinberg, 1997

13. Yosef Zohar, 2017

In addition to Sergiu Hart, four of them also were plenary speakers at GTM conferences: Shmuel Zamir (2011), Abraham Neyman (2014), David Schmeidler (2015), Dov Samet (2018). The list of pleanary speakers of GTM conferences also includes Eilon Solan (2016), a talented descendant of the second generation who was a student of Abraham Neyman. 
Aumann's contributions to the field of game theory could not be overemphasized. His greatest contribution is in the realm of repeated games. In the period of 1966-68 he, together with Michael Maschler, as members of a group at the United States Arms Control and Disarmament Agency (ACDA) developed the theory of repeated games with incomplete information. The mission of this group was to study the decision theoretic aspects of the arms control and disarmament.

Aumann was the first to define the concept of correlated equilibrium in game theory, a type of equilibrium in non-cooperative games.

Furthermore, Aumann has introduced the first purely formal account of the notion of common knowledge in game theory. He collaborated with Lloyd Shapley on the Aumann-Shapley value.

He is also known for his agreement theorem, in which he argues that under certain assumptions, two Bayesian rational agents with common prior beliefs cannot agree to disagree.

Aumann used and continues to use game theory to analyze Talmudic dilemmas.

\section{List of publications of R.J. Aumann}

(I) Books

1. R.J. Aumann, L.S. Shapley, Values of Non-Atomic Games, Princeton University Press, Princeton, 1974, xi +333 pp.

2. R.J. Aumann, Y. Tauman and S. Zamir, Game Theory (in Hebrew), Everyman's University, Tel Aviv, 1981, Vol 1: 211 pp., Vol 2: 203 pp.

3. R.J. Aumann, Lectures on Game Theory, Underground Classics in Economics, Westview Press, Boulder, 1989, ix +120 pp.

4. Handbook of Game Theory with economic applications, Vol 1, 1992, xxvi + 733 pp., Vol 2, 1994, xxviii + 787 pp., Vol 3, 2002, xxx + 858 pp., Elsevier, Amsterdam (coedited with S. Hart).

5. R.J. Aumann, M. Maschler, Repeated Games with Incomplete Information, MIT Press, Cambridge, 1995, xvii +342 pp.

6. R.J. Aumann, Collected Papers, Vol 1, xi +786 pp., Vol 2, xiii +792 pp., MIT Press, Cambridge, 2000.

(II) Articles

1. R.J. Aumann, "Asphericity of Alternating Knots", Annals of Mathematics 64 (1956), pp. 374-392.

2. R.J. Aumann, J.B. Kruskal, "The Coefficients in an Allocation Problem", Naval Research Logistics Quarterly 5 (1958), pp. 111-123.

3. R.J. Aumann, J.B. Kruskal, "Assigning Quantitative Values to Qualitative Factors in the Naval Electronics Problem", Naval Research Logistics Quarterly 6 (1959), pp. 1-16.

4. R.J. Aumann, "Acceptable Points in General Cooperative n-Person Games", in Contributions to the Theory of Games IV, Annals of Mathematics Study 40, edited by A. W. Tucker and R. D. Luce, Princeton University Press, 1959, pp. $287-324$. 
5. R.J. Aumann, B. Peleg, "Von Neumann-Morgenstern Solutions to Cooperative Games without Side Payments", Bulletin of the American Mathematical Society 66 (1960), pp. 173-179.

6. R.J. Aumann, "Acceptable Points in Games of Perfect Information", Pacific Journal of Mathematics 10 (1960), pp. 381-417.

7. R.J. Aumann, "A Characterization of Game Structures of Perfect Information", Bulletin of the Research Council of Israel 9F (1960), pp. 43-44.

8. R.J. Aumann, "Spaces of Measurable Transformations", Bulletin of the American Mathematical Society 66 (1960), pp. 301-304.

9. R.J. Aumann, "Linearity of Unrestrictedly Transferable Utilities", Naval Research Logistics Quarterly 7 (1960), pp. 281-284.

10. R.J. Aumann, "The Core of a Cooperative Game without Side Payments", Transactions of the American Mathematical Society 98 (1961), pp. 539-552.

11. R.J. Aumann, "Borel Structures for Function Spaces", Illinois Journal of Mathematics 5 (1961), pp. 614-630.

12. R.J. Aumann, "Almost Strictly Competitive Games", Journal of the Society for Industrial and Applied Mathematics 9 (1961), pp. 544-550.

13. (a)R.J. Aumann, "Utility Theory without the Completeness Axiom", Econometrica 30 (1962), pp. 445-462.

(b)R.J. Aumann, "Utility Theory without the Completeness Axiom: A Correction", Econometrica 32 (1964), pp. 210-212.

(c)R.J. Aumann, "Another Corrigendum to 'Utility Theory without the Completeness Axiom" ", Econometrica 87 (2019), Online Article Comments, https://doi.org/10.3982/ECTA17181.

14. F.J. Anscombe, R.J. Aumann, "A Definition of Subjective Probability", Annals of Mathematical Statistics 34 (1963), pp. 199-205.

15. R.J. Aumann, "On Choosing a Function at Random", in Ergodic Theory, edited by F. W. Wright, Academic Press, 1963, pp. 1-20.

16. R.J. Aumann, "Markets with a Continuum of Traders", Econometrica 32 (1964), pp. 39-50.

17. R.J. Aumann, M. Maschler, "The Bargaining Set for Cooperative Games", in Advances in Game Theory, Annals of Mathematics Study 52, edited by M. Dresher, L. S. Shapley, and A. W. Tucker, Princeton University Press, 1964, pp. 443-476.

18. R.J. Aumann, "Mixed and Behavior Strategies in Infinite Extensive Games", in Advances in Game Theory, Annals of Mathematics Study 52, edited by M. Dresher, L. S. Shapley, and A. W. Tucker, Princeton University Press, 1964, pp. 627-650.

19. R.J. Aumann, "Subjective Programming", in Human Judgments and Optimality, edited by M. W. Shelly and G. I. Bryan, John Wiley and Sons, New York, 1964, pp. 217-242.

20. R.J. Aumann, M. Perles, "A Variational Problem Arising in Economics", Journal of Mathematical Analysis and Applications 11 (1965), pp. 488-503.

21. R.J. Aumann, "Integrals of Set-Valued Functions", Journal of Mathematical Analysis and Applications 12 (1965), pp. 1-12. 
22. R.J. Aumann, B. Peleg and P. Rabinowitz, "A Method of Computing the Kernel of n-Person Games", Mathematics of Computation 19 (1965), pp. $531-551$.

23. R.J. Aumann, "Existence of Competitive Equilibria in Markets with a Continuum of Traders", Econometrica 34 (1966), pp. 1-17.

24. R.J. Aumann, "A Survey of Cooperative Games without Side Payments", in Essays in Mathematical Economics in Honor of Oskar Morgenstern, edited by M. Shubik, Princeton University Press, 1967, pp. 3-27.

25. R.J. Aumann, "Random Measure Preserving Transformations", in Proceedings of the Fifth Berkeley Symposium on Mathematical Statistics and Probability, Vol II, Part 2, edited by L. M. LeCam and J. Neyman, University of California Press, 1967, pp. 321-326.

26. R.J. Aumann, "Measurable Utility and the Measurable Choice Theorem", in La Decision, Editions du Centre National de la Recherche Scientifique, 1969, pp. $15-26$.

27. R.J. Aumann, M. Maschler, "Some Thoughts on the Minimax Principle", Management Science 18 (1972), pp. 54-63.

28. R.J. Aumann, "Disadvantageous Monopolies", Journal of Economic Theory 6 (1973), pp. 1-11.

29. R.J. Aumann, "Subjectivity and Correlation in Randomized Strategies", Journal of Mathematical Economics 1 (1974), pp. 67-96.

30. R.J. Aumann, B. Peleg, "A Note on Gale's Example", Journal of Mathematical Economics 1 (1974), pp. 209-211.

31. R.J. Aumann, J. Dreze, "Cooperative Games with Coalition Structures", International Journal of Game Theory 3 (1974), pp. 217-237.

32. R.J. Aumann, "Values of Markets with a Continuum of Traders", Econometrica 43 (1975), pp. 611-646.

33. R.J. Aumann, "An Elementary Proof that Integration Preserves Uppersemicontinuity", Journal of Mathematical Economics 3 (1976), pp. 15-18.

34. R.J. Aumann, "Agreeing to Disagree", Annals of Statistics 4 (1976), pp. 12361239.

35. R.J. Aumann, U. Rothblum, "Orderable Set Functions and Continuity III: Orderability and Absolute Continuity", SIAM Journal on Control and Optimization 15 (1977), pp. 156-162.

36. R.J. Aumann, "The St. Petersburg Paradox: A Discussion of Some Recent Comments", Journal of Economic Theory 14 (1977), pp. 443-445.

37. R.J. Aumann, M. Kurz, "Power and Taxes", Econometrica 45 (1977), pp. 1137-1161.

38. R.J. Aumann, M. Kurz, "Power and Taxes in a Multi-Commodity Economy", Israel Journal of Mathematics 27 (1977), pp. 185-234.

39. R.J. Aumann, R. J. Gardner and R. W. Rosenthal, "Core and Value for a Public Goods Economy: An Example", Journal of Economic Theory 15 (1977), pp. 363-365.

40. R.J. Aumann, "On the Rate of Convergence of the Core", International Economic Review 19 (1979), pp. 349-357. 
41. R.J. Aumann, "Recent Developments in the Theory of the Shapley Value", in Proceedings of the International Congress of Mathematicians, Helsinki, 1978, edited by O. Lehto, Academia Scientiarum Fennica, 1980, pp. 995-1003.

42. R.J. Aumann, "Survey of Repeated Games", in Essays in Game Theory and Mathematical Economics in Honor of Oskar Morgenstern, Vol 4 of Gesellschaft, Recht, Wirtschaft, Wissenschaftsverlag, edited by V. Bohm, Bibliographisches Institut, Mannheim, 1981, pp. 11-42.

43. R.J. Aumann, Y. Katznelson, R. Radner, R. W. Rosenthal, and B. Weiss, "Approximate Purification of Mixed Strategies", Mathematics of Operations Research 8 (1983), pp. 327-341.

44. R.J. Aumann, M. Kurz and A. Neyman, "Voting for Public Goods", Review of Economic Studies 50 (1983), pp. 677-694.

45. R.J. Aumann, "An Axiomatization of the Non-Transferable Utility Value", Econometrica 53 (1985), pp. 599-612.

46. R.J. Aumann, M. Maschler, "Game-Theoretic Analysis of a Bankruptcy Problem from the Talmud", Journal of Economic Theory 36 (1985), pp. 195213.

47. R.J. Aumann, "What Is Game Theory Trying to Accomplish?", in Frontiers of Economics, edited by K. Arrow and S. Honkapohja, Basil Blackwell, Oxford, 1985, pp. $28-76$.

48. R.J. Aumann, "On the Non-Transferable Utility Value: A Comment on the Roth-Shafer Examples", Econometrica 53 (1985), pp. 667-677.

49. R.J. Aumann, "Rejoinder", Econometrica 54 (1986), pp. 985-989.

50. R.J. Aumann, S. Hart, "Bi-Convexity and Bi-Martingales", Israel Journal of Mathematics 54 (1986), pp. 159-180.

51. R.J. Aumann, J. Dreze, "Values of Markets with Satiation or Fixed Prices", Econometrica 54 (1986), pp. 1271-1318.

52. R.J. Aumann, M. Kurz and A. Neyman, "Power and Public Goods", Journal of Economic Theory 42 (1987), pp. 108-127.

53. R.J. Aumann, "Correlated Equilibrium as an Expression of Bayesian Rationality", Econometrica 55 (1987), pp. 1-18.

54. R.J. Aumann, "Value, Symmetry, and Equal Treatment: A Comment on Scafuri and Yannelis", Econometrica 55 (1987), pp. 1461-1464.

55. R.J. Aumann, "Game Theory", in The New Palgrave, A Dictionary of Economics, Vol 2, edited by J. Eatwell, M. Milgate, and P. Newman, Macmillan, London and Basingstoke, 1987, pp. 460-482.

56. R.J. Aumann, R. Myerson, "Endogenous Formation of Links between Players and of Coalitions: An Application of the Shapley Value", in The Shapley Value: Essays in Honor of Lloyd S. Shapley, edited by A. E. Roth, Cambridge University Press, Cambridge, 1988, pp. 175-191.

57. R.J. Aumann, S. Sorin, "Cooperation and Bounded Recall", Games and Economic Behavior 1 (1989), pp. 5-39.

58. R.J. Aumann, "CORE as a Macrocosm of Game-Theoretic Research, 19671987", in Contributions to Operations Research and Economics: The Twentieth Anniversary of CORE, edited by B. Cornet and H. Tulkens, MIT Press, Cambridge and London, 1989, pp. 5-16. 
59. R.J. Aumann, "Nash Equilibria are not Self-Enforcing", in Economic Decision Making: Games, Econometrics and Optimisation (Essays in Honor of Jacques Dreze), edited by J. J. Gabszewicz, J.-F. Richard, and L. Wolsey, Elsevier Science Publishers, Amsterdam, 1990, pp. 201-206.

60. R.J. Aumann, "Irrationality in Game Theory", in Economic Analysis of Markets and Games (Essays in Honor of Frank Hahn), edited by P. Dasgupta, D. Gale, O. Hart, and E. Maskin, MIT Press, Cambridge and London, 1992, pp. $214-227$.

61. R.J. Aumann, L.S. Shapley, "Long-Term Competition: A Game-Theoretic Analysis", in Essays in Game Theory in Honor of Michael Maschler, edited by N. Megiddo, Springer, New York, 1994, pp. 1-15.

62. R.J. Aumann, "The Shapley Value", in Game-Theoretic Methods in General Equilibrium Analysis, edited by J.-F. Mertens and S. Sorin, Kluwer Academic Publishers, Dordrecht, 1994, pp. 61-66.

63. R.J. Aumann, "Economic Applications of the Shapley Value", in Game-Theoretic Methods in General Equilibrium Analysis, edited by J.-F. Mertens and S. Sorin, Kluwer Academic Publishers, Dordrecht, 1994, pp. 121-133.

64. R.J. Aumann, "Backward Induction and Common Knowledge of Rationality", Games and Economic Behavior 8 (1995), pp. 6-19.

65. R.J. Aumann, A. Brandenburger, "Epistemic Conditions for Nash Equilibrium", Econometrica 63 (1995), pp. 1161-1180.

66. R.J. Aumann, "Reply to Binmore", Games and Economic Behavior 17 (1996), pp. $138-146$.

67. R.J. Aumann, "Reply to Margalit and Yaari", in The Rational Foundations of Economic Equilibrium, edited by K. J. Arrow, E. Colombatto, M. Perlman, and C. Schmidt, Macmillan, London and Basingstoke, 1996, pp. 106-107.

68. R.J. Aumann, "Reply to Binmore and Samuelson", in The Rational Foundations of Economic Equilibrium, edited by K. J. Arrow, E. Colombatto, M. Perlman, and C. Schmidt, Macmillan, London and Basingstoke, 1996, pp. 130131.

69. R.J. Aumann, S. Hart and M. Perry, "The Absent-Minded Driver", Games and Economic Behavior 20 (1997), pp. 102-116.

70. R.J. Aumann, S. Hart and M. Perry, "The Forgetful Passenger", Games and Economic Behavior 20 (1997), pp. 117-120.

71. R.J. Aumann, "Rationality and Bounded Rationality", Games and Economic Behavior 21 (1997), pp. 2-14.

72. R.J. Aumann, "On the Centipede Game", Games and Economic Behavior 23 (1998), pp. 97-105.

73. R.J. Aumann, "Common Priors: A Reply to Gul", Econometrica 66 (1998), pp. 929-938.

74. R.J. Aumann, "Interactive Epistemology I: Knowledge", International Journal of Game Theory 28 (1999), pp. 263-300. 
75. R.J. Aumann, "Interactive Epistemology II: Probability", International Journal of Game Theory 28 (1999), pp. 301-314.

76. R.J. Aumann, W. Gueth, "Species Survival and Evolutionary Stability in Sustainable Habitats", Journal of Evolutionary Economics 10 (2000), pp. 437447.

77. R.J. Aumann, "The Rationale for Measurability", in Economics Essays, A Festschrift for Werner Hildenbrand, edited by G. Debreu, W. Neuefeind, and W. Trockel, Springer, Berlin, 2001, pp. 5-7.

78. R.J. Aumann, "Harsanyi's Sweater", Games and Economic Behavior 36 (2001), pp. $7-8$.

79. R.J. Aumann, A. Heifetz, "Incomplete Information", in Handbook of Game Theory with economic applications, Vol 3, edited by R. J. Aumann and S. Hart, Elsevier, Amsterdam, 2002, pp. 1665-1686.

80. R.J. Aumann, "Risk Aversion in the Talmud", Economic Theory 21 (2003), pp. 233-239.

81. R.J. Aumann, "Presidential Address", Games and Economic Behavior 45 (2003), pp. 2-14.

82. R.J. Aumann, S. Hart, "Long Cheap Talk", Econometrica 71 (2003), pp. 1619-1660.

83. R.J. Aumann, "Musings on Information and Knowledge", Econ Journal Watch (2005), pp. 88-96.

84. R.J. Aumann, "War and Peace", in Les Prix Nobel 2005, edited by K. Grandin, The Nobel Foundation, Stockholm, 2006, pp. 350-358.

85. R.J. Aumann, "Consciousness", in Life as We Know It, edited by J. Seckbach, Springer, Dordrecht, 2006, pp. 555-564.

86. R.J. Aumann, J. Dreze, "Rational Expectations in Games", American Economic Review 98 (2008), pp. 72-86.

87. R.J. Aumann, "Game Engineering", in Mathematical Programming and Game Theory for Decision Making, edited by S. K. Neogy, R. B. Bapat, A. K. Das, and T. Parthasarathy, World Scientific, Singapore, 2008, pp. 279-286.

88. R.J. Aumann, "Working with Mike", Games and Economic Behavior 64 (2008), pp. $355-360$.

89. R.J. Aumann, R. Serrano, "An Economic Index of Riskiness", Journal of Political Economy 116 (2008), pp. 810-836.

90. R.J. Aumann, J. Dreze, "Assessing Strategic Risk", American Economic Journal: Microeconomics 1 (2009), pp. 1-16.

91. R.J. Aumann, "A Response Regarding the Matter of the Man with Three Wives", Hama'yan 50, 2, Tevet 5770 (January 2010), pp. 1-11 (In Hebrew).

92. R.J. Aumann, "Some Non-Superadditive Games, and Their Shapley Values, in the Talmud", International Journal of Game Theory 39 (2010), pp. 3-10.

93. R.J. Aumann, "On the Matter of the Man with Three Wives: Part Two and a Reply to Responders", Hama'yan 50, 4, Tamuz 5770 (June 2010), pp. 49-69 (In Hebrew).

94. (a)R.J. Aumann, "My Scientific First-Born", International Journal of Game Theory 41 (2012), pp. 735-736.

(b) R.J. Aumann, "My Scientific First-Born: A Clarification", International Journal of Game Theory 48 (2019), pp. 999-1000. 
95. I. Arieli, R.J. Aumann, "The Logic of Backward Induction", Journal of Economic Theory 159 (2015), pp. 443-464.

96. R.J. Aumann, "Rav Ha'i Gaon's Position on the Three Wives and the Three Partners", Hama'yan 58, 3, Nissan 5778 (March 2018), pp. 33-44 (in Hebrew).

97. R.J. Aumann, "A Synthesis of Behavioural and Mainstream Economics", Nature Human Behavior 3 (2019), pp. 666-670 .

98. R.J. Aumann, Yehonatan Aumann and Shoham Baris, "The Khida's position on Kavua and Parish,"Hama'yan 60, 3, Nissan 5780 (March 2020), pp. 3-16 (in Hebrew).

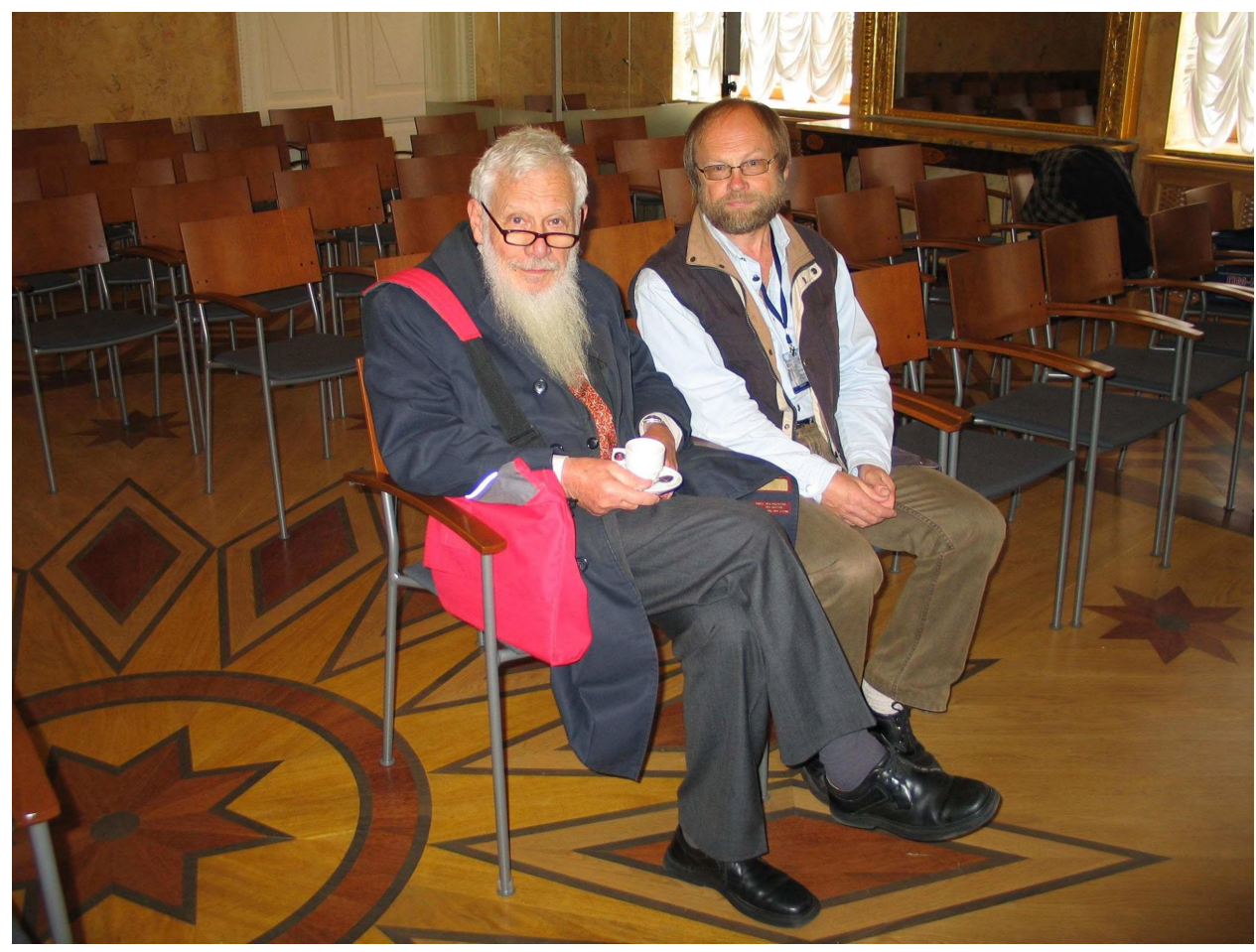

R. Aumann and V. Mazalov on GTM2007 in Saint-Petersburg State University 